\title{
Neuropeptide delivery to the brain: a von Willebrand factor signal peptide to direct neuropeptide secretion
}

\author{
Marijke WA de Backer, Maike AD Brans, Mieneke CM Luijendijk, Keith M Garner, Dianne MA van den Heuvel, \\ R Jeroen Pasterkamp, Roger AH Adan
}

\begin{abstract}
Background: Multiple neuropeptides, sometimes with opposing functions, can be produced from one precursor gene. To study the roles of the different neuropeptides encoded by one large precursor we developed a method to overexpress minigenes and establish local secretion.

Results: We fused the signal peptide from the Von Willebrand Factor (VWF) to a furin site followed by a processed form of the Agouti related protein (AgRP), AgRP $83-132$ or $\alpha$-melanocyte stimulating hormone. In vitro, these minigenes were secreted and biologically active. Additionally, the proteins of the minigenes were not transported into projections of primary neurons, thereby ensuring local release. In vivo administration of WWF-AgRP ${ }_{83-132}$, using an adeno-associated viral vector as a delivery vehicle, into the paraventricular hypothalamus increased body weight and food intake of these rats compared to rats which received a control vector.

Conclusions: This study demonstrated that removal of the N-terminal part of full length AgRP and addition of a WWF signal peptide is a successful strategy to deliver neuropeptide minigenes to the brain and establish local neuropeptide secretion.
\end{abstract}

\section{Background}

Numerous neuropeptide precusors have been implicated in the regulation of energy balance, such as pro-opiomelanocortin (POMC), melanin concentrating hormone $(\mathrm{MCH})$ and ghrelin. Neuropeptide precursors have a propeptide which translocates the neuropeptide precursors from the rough-endoplasmatic reticulum to the trans-golgi network (TGN). From the TGN the peptide precursors traffic into immature secretory vesicles where they are cleaved once or multiple times by prohormone convertases (PC) $1 / 3$ and/or 2 to generate functional neuropeptides [1-3]. Through budding and fusion the immature vesicles become mature, dense, vesicles which release their content upon a specific signal [4].

The processing of neuropeptide precursors results in multiple biologically active peptides, sometimes with opposing effects; an example is the POMC gene. Pre-

\footnotetext{
* Correspondence: r.a.h.adan@umcutrecht.nl

Rudolf Magnus Institute of Neuroscience, Department of Neuroscience and Pharmacology, Utrecht University Medical Centre Utrecht, Utrecht, the Netherlands
}

pro POMC is processed into several neuropeptides with anorexigenic functions, e.g. $\alpha$-melanocyte stimulating hormone (MSH) and $\beta-\mathrm{MSH}$, but also into an opioid with "orexigenic" function, namely $\beta$-endorphin [5-9]. Loss of the whole POMC gene results in hyperphagia and obesity [10]. Although there is strong evidence that the lack of melanocortin signaling in POMC knockout mice explains the phenotype, mice lacking only the $\beta$-endorphin part of the POMC gene are also hyperphagic and obese [11]. Another example of a precursor gene that encodes for peptides with diverse effects is pre-pro-ghrelin which encodes for ghrelin, an appetite stimulating hormone, and obestatin, an appetite suppressing hormone [12]. Therefore, it is important to determine the role of individual neuropeptides encoded by a precursor gene.

To investigate the role of specific neuropeptides, synthesized neuropeptides can be injected through intracerebroventricular (ICV) or local cannulae in the brain. However, there are drawbacks to these techniques. ICV administration of neuropeptides can be done long term, 
but administration is not local. In contrast, neuropeptides remain local with local cannulae, but these experiments are usually short term, because the cannulae can not be maintained over weeks. To overexpress neuropeptides locally and for long periods of time one can use viral vectors, such as adeno-associated viral (AAV) vectors [13-15]. There are two problems with the long term overexpression of neuropeptide genes. Firstly, the precursor gene encodes for multiple peptides, which may serve different functions (see above). Therefore, overexpression of the precursor gene may show the effects multiple peptides. The second problem, with overexpression of neuropeptides via viral vectors, is that the neuropeptide is potentially released in an area to which the transduced neuron projects rather than secretion locally at the site of transduction; with AAV mediated overexpression of neuropeptide Y (NPY) in the paraventricular nucleus $(\mathrm{PVN})[13,16]$ the release of NPY may thus not be limited to the PVN. In the hypothalamus there are many interneurons and local connections, therefore NPY will probably be secreted locally. However, even in the absence of staining in the projection areas one can not exclude that a projection neuron is releasing the neuropeptide elsewhere.

In order to circumvent that overexpression of a neuropeptide gene generates multiple messages and that the peptide may be released at distant sites, we developed an AAV vector based method to overcome these problems. In short, we fused a signal peptide with HA tag and furin site to the cDNA of a specific minigene, namely $\mathrm{AgRP}_{83-132}$ or $\alpha-\mathrm{MSH}$. To prevent trafficking of the minigene into the regulated secretion pathway we removed the N-terminal part of AgRP or only used the $\mathrm{MSH}$ sequence and made a construct in which a signal peptide from the Von Willebrand Factor (VWF) was used to enter the endoplasmic reticulum [17,18]. A furin cleavage site was inserted between the signal peptide$\mathrm{HA}$ tag and the minigene to release the minigene from the signal peptide. Furin is a ubiquitously expressed PC which is located in the TGN, in stead of in secretory vesicles, and cycles back and forth to the plasma membrane [19-21]. We used the cDNA of $\operatorname{AgRP}_{83-132}$ as a minigene, because this is the main secreted form of AgRP after processing by PC [22]. AgRP is an inverse agonist for the MC3R and MC4R and stimulates food intake and reduces energy expenditure, while $\alpha-\mathrm{MSH}$ is a peptide derived from the POMC gene and is able to activate the MC3R and MC4R to inhibit food intake and increase energy expenditure [5,23-26]. AgRP and $\alpha$ MSH compete to bind to the MC4R and the balance between these peptides determines the activity of the MC4R.

\section{Results}

VWF-AgRP $_{83-132}$ and VWF- $\alpha M S H$ are secreted and biologically active

To investigate if peptides produced from constructs with a VWF signal peptide followed by a cleavage site and a neuropeptide are secreted and are biologically active, we tested whether the medium of cells transfected with the VWF-AgRP ${ }_{83-132}$ constructs was able to antagonize the MC4R. The ability of the VWF-AgRP ${ }_{83-132}$ to shift the NDP-MSH dose reponse curve to the right was compared to a construct encoding for full length AgRP, containing the normal AgRP signal peptide. Activation of MC4R in vitro results in an increase in cyclic adenosine monophosphate (cAMP)[27]. In our assay upregulation of cAMP increased LacZ expression through a cAMP responsive element.

Addition of NDP-MSH to MC4R and CRE-LacZ transfected cells resulted in a dose response curve with an $\mathrm{EC}_{50}$ value of $0.1 \mathrm{nM}\left(1 \times 10^{-10}\right)$. Another control was the addition of forskolin to MC4R_Cre-LacZ transfected cells (Figure 1A). Forskolin directly activates adenylyl cyclase, thereby increasing cAMP (control for transfection of MC4R and CRE-LacZ). When supernatants of GFP transfected cells were added together with different concentrations of NPD-MSH to MC4R_CRELacZ transfected cells, the dose response curve did not alter. However, addition of supernatants of flAgRP or VWF-AgRP ${ }_{83-132}$ transfected cells shifted the NDP-MSH dose response curve to the right. The $\mathrm{EC}_{50}$ decreased to 1.4 and $0.5 \mathrm{nM}$, respectively when $10 \%$ of the volume added was supernatant (Figure 1B). When $50 \%$ of the volume added to the MC4R_CRE-LacZ cells was supernatant from flAgRP or VWF-AgRP ${ }_{83-132}$ the NDP-MSH dose response curve shifted even further to the right (Figure 1C). In order to determine the amount of secreted AgRP protein, supernatants were analyzed on a spot blot (data not shown). This blot showed that 18.2fold less AgRP was secreted from the VWF-AgRP $83-132$ transfected cells compared to flAgRP transfected cells, even though the transfection efficiencies were similar.

To check if monomeric VWF- $\alpha$ MSH1 and polymeric VWF- $\alpha$ MSH4 were able to activate the MC4R, different dilutions of supernatants from cells transfected with these constructs were added to MC4R_CRE-LacZ transfected cells. Supernatants of both constructs activated the MC4R, with the polymeric VWF- $\alpha$ MSH4 being more potent. The polymeric VWF- $\alpha \mathrm{MSH} 4$ reached $50 \%$ of MC4R activation at a dilution of 216 times, while VWF- $\alpha$ MSH1 already reached $50 \%$ activation of MC4-R after 10.7 times dilution. The supernatant of GFP transfected cells was not able to activate the MC4R (Figure $1 \mathrm{D}, \mathrm{E})$. 


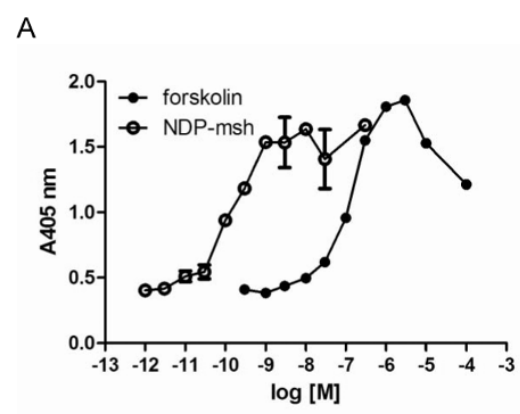

B

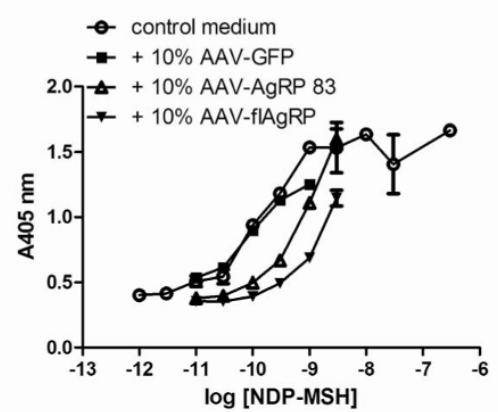

D

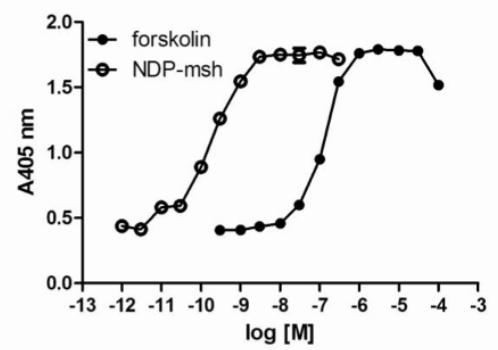

C

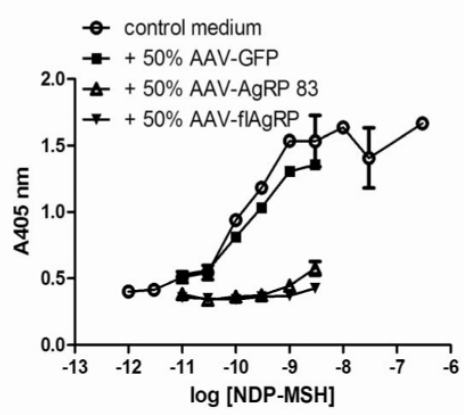

E

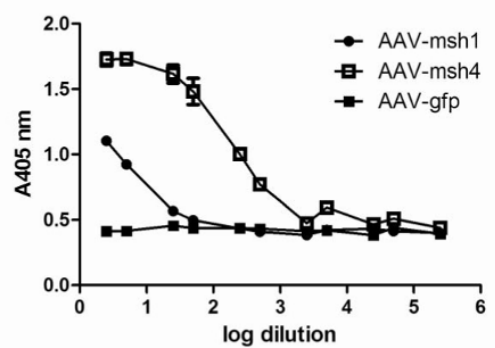

Figure 1 VWF-proteins are secreted and biologically active. A: Dose-response curve of NDP-MSH and forskolin showing their ability to stimulate 293T cells transfected with MC4R and CAMP sensitive reporter gene. B: similar as 2A, but in the presence of 10\% of conditioned medium from 293T cells transfected with either AAV-GFP, AAV-flAgRP or AAV-VWF-AgRP 83-132. C: similar as 2B, but with 50\% of conditioned medium. D: dose-response curve of NDP-MSH and forskolin as positive control for MC4R and CRE-LacZ transfection. E: response curve of cells transfected with MC4R and CRE-LacZ incubated with different dilutions of conditioned medium. Medium was taken from cells transfected with AAV-GFP, AAV-MSH1 or AAV-MSH4. Graphs represent an average of 4 trials.

\section{Localization of flAgRP and VWF-AgRP ${ }_{83-132}$ in primary neurons}

We compared the localization of AgRP in primary cortical neurons which were infected with AAV-flAgRP or AAVVWF-AgRP $83-132$ to check if AAV-VWF-AgRP $83-132$ entered the regulated secretion pathway. Three days after infection the primary cortical neurons were stained for AgRP. In addition, $\beta$-tubulin-III was used to stain the cytoskeleton of neurons and DAPI to identify the cell nucleus. Neurons transduced with AAV-flAgRP, which contained the endogenous signal peptide to target AgRP into the regulated secretory pathways, showed AgRP immunostaining in their cell bodies and their branches. In contrast, AAV-VWF-AgRP $83-132$ transduced neurons only showed AgRP immunostaining in the cell bodies and almost no staining in the branches (Figure 2). We did not observe GFP signal without GFP immunostaining.

\section{Behavioral effects of AAV-VWF-AgRP ${ }_{83-132}$}

To further prove the functionality of AAV-VWF$\mathrm{AgRP}_{83-132}$, this virus was also injected in the PVN of rats. One $\mu$ l containing $1 \times 10^{9}$ genomic copies of AAVVWF-AgRP ${ }_{83-132}$ or AAV-GFP (as control) was injected in the PVN (Figure 3A). In situ hybridization against GFP showed that the PVN was transduced (unilaterally). Overexpression of AAV-VWF- AgRP $83-132$ increased daily food intake when compared to titer matched AAV-GFP injected rats $(p=0.049)$ (Figure 3B). In addition, the AAV-VWF-AgRP $83-132$ rats showed a significant increase in body weight gain compared to 

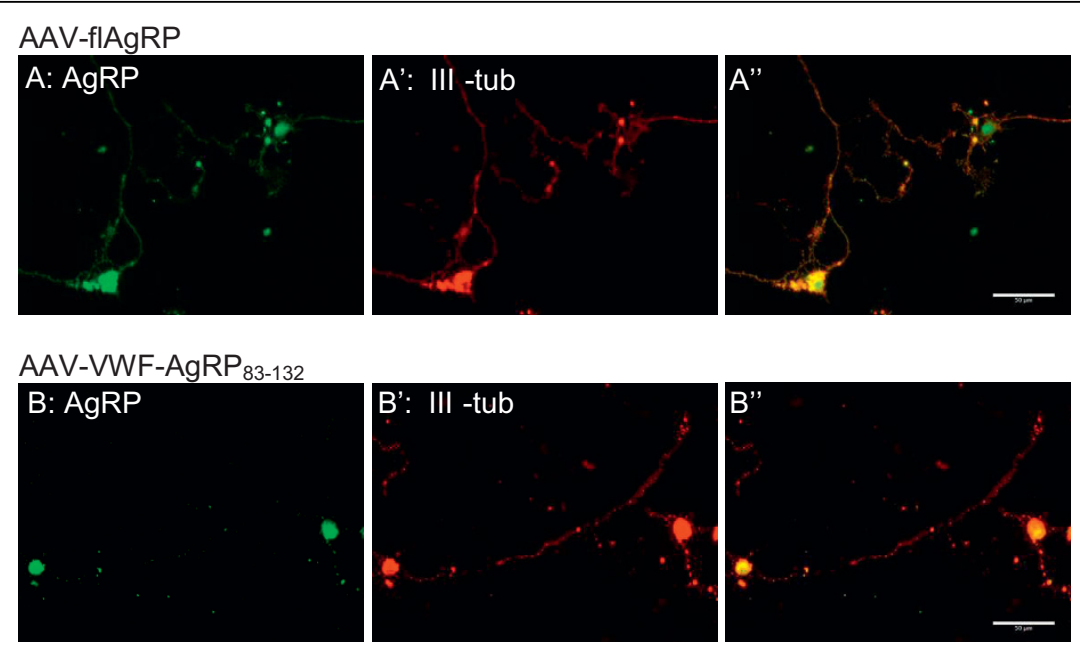

Figure 2 Fluorescent immunostaining showing the localization of flAgRP versus VWF-AgRP $\mathbf{8 3 - 1 3 2}$. Primary cortical neurons were infected with AAV-fIAgRP(A) or AAV-WWF-AgRP ${ }_{83-132}$ (B) at a multiplicity of infection of 10.000 . Seventy hours after infection neurons were fixed and immunostained for AgRP (green) and $\beta$ III-tubulin (red). "shows the overlay of green and red signals.

AAV-GFP rats $(\mathrm{p}=0.0032)$ from day 0 until day 28 post injection (Figure 3C).

\section{Discussion}

We here successfully demonstrate a novel approach to locally overexpress a individual neuropeptide rather than a whole neuropeptide precursor. This was achieved by fusing a neuropeptide minigene to the VWF signal peptide in a rAAV vector. We demonstrated that the neuropeptide minigene was released from the cell body and did not enter the regulated secretory pathway in vitro. In addition, we showed that the delivery of the neuropeptide minigene, using AAV, to neurons of the PVN resulted in an increased food intake and body weight.

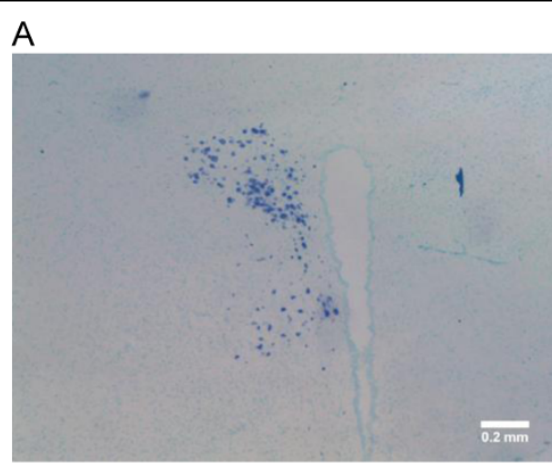

B

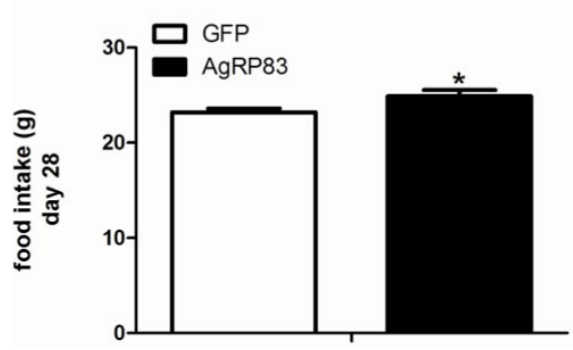

C

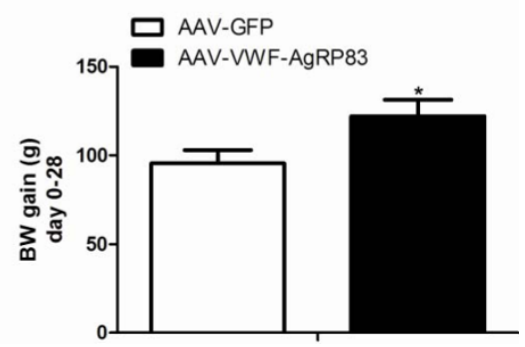

Figure 3 In vivo effects of $\mathbf{A A V}_{\mathbf{V}} \mathbf{V W F} \mathrm{AgRP}_{\mathbf{8 3 - 1 3 2}}$ on energy balance. In situ hybridization showing unilateral transduction of the PVN by $1 \mu \mathrm{l}$, containing $1 \times 10^{9}$ g.c., of AAV-WWF-AgRP $83-132$ (A). AAV-WWF-AgRP $83-132$ increased food intake (B) and BW gain (C) compared to AAV-GFP. Data at 28 days post injection $(N=3)$. 
This demonstrated that this method to deliver AgRP locally in the brain was effective.

Previous studies have shown that specific signal peptides could route a protein to the regulated pathway. Fusion of GFP to NPY or insulin signal sequence was sufficient to route GFP to regulated secretory granules and resulted in GFP secretion at axon terminals [28,29]. In addition, other groups have already showed that a secretory signal peptide can be used to direct constitutive peptide secretion from an AAV vector in the rat brain $[30,31]$. In this study we showed that it is also possible to route peptides into the constitutive secretion pathway resulting in secretion by the cell body, through the use of the VWF signal peptide and an AgRP fragment that lacked the $\mathrm{N}$ terminal part. We replaced the endogenous signal peptide, $\mathrm{N}$-terminal part and cleavage site for a VWF signal peptide and a canonical proteolytic cleavage site for furin. Normally the VWF is processed in endothelial cells, however AAV transduces mainly neurons. Therefore, after the VWF signal peptide a furin recognition site (RKRR) was inserted, this to ensure that the VWF signal peptide was cleaved from $\mathrm{AgRP}_{83-132}$ in neurons. Probably the removal of the $\mathrm{N}$-terminal part of the AgRP gene has resulted to constitutive secretion, since it is suggested that the Nterminal part of prohormone neuropeptides in involved in the sorting to the secretory or constitutive pathway. To obtain long term expression of the neuropeptide minigenes we embedded these DNA constructs in an rAAV vector. During our study a paper was published which described a method to deliver two gene products, GFP and galanin, from one rAAV vector [32]. They placed a furin sequence between the two genes and the first gene was fused to a fibronectin secretory signal peptide to establish constitutive secretion. This confirmed the feasibility of using furin as a cleavage site.

First we investigated if the vectors with the VWF signal peptide are secreted into the medium and compared this with a vector with its endogenous signal peptide.

The MC4R_CRE-LacZ assay showed that VWFAgRP $_{83-132}$ and VWF- $\alpha M S H 1$ and VWF- $\alpha$ MSH4 were secreted by $293 \mathrm{~T}$ cells into the culture medium. The secreted peptides were also biologically active since the medium could, respectively, inhibit or activate the MC4R. The medium of cells transfected with flAgRP vector, containing the endogenous AgRP signal peptide, also inhibited the MC4R. However, the inhibition by flAgRP was stronger than the inhibition caused by medium from VWF-AgRP ${ }_{83-132}$ transfected cells. After the MC4R assay we determined the amount of protein secreted in the medium of the cells. This revealed that there was 18.2 fold less AgRP immunoreactivity in the medium of VWF-AgRP ${ }_{83-132}$ transfected cells than in the medium of flAgRP. The difference in potency between VWF-AgRP $83-132$ and flAgRP to antagonize NDP-MSH, 0.5 versus $1.4 \mathrm{nM}$ respectively, is in the range which we expected, since a study by Creemers et. al. showed that $\mathrm{AgRP}_{83-132}$ was 6.1 fold more potent than flAgRP in inhibiting the MC4R [22]. Thus, given the amount of peptide release (18.2 fold less secretion of VWF-AgRP ${ }_{83-132}$ than flAgRP) and potencies (VWF$\operatorname{AgRP}_{83-132}$ approximately 3 times less potent than flAgRP) our results are in agreement with the study by Creemers et al. that VWF-AgRP ${ }_{83-132}$ is 6 times more potent than flAgRP.

Medium from cells transfected with AAV-VWF$\alpha \mathrm{MSH} 4$ was more potent in activating MC4R_CRELacZ than medium from AAV-VWF- $\alpha$ MSH1 transfected cells. Medium from GFP transfected cells was not able to stimulate MC4R_CRE-LacZ. These data are in agreement with previous data [33].

In addition, we compared the localization of flAgRP and VWF-AgRP ${ }_{83-132}$ in primary neuronal cultures. These results showed that flAgRP was expressed in the cell body and in the projections and that VWF-AgRP ${ }_{83-132}$ was only expressed in the cell body and not in the projections. These results were in agreement with the expectation: peptides coupled to the VWF signal peptide and lacking the $\mathrm{N}$-terminal part of AgRP entered the constitutive secretion pathway and the one coupled to the endogenous AgRP signal peptide plus $\mathrm{N}$-terminal part entered the regulated secretion pathway in axons.

As a proof of principle we showed that unilateral overexpression with the VWF-AgRP $83-132 \mathrm{AAV}$ vector in a target area of AgRP neurons, the PVN, increased food intake. This showed that the VWF-AgRP ${ }_{83-132}$ is also functional in vivo.

\section{Conclusions}

This study showed that it is possible to overexpress a single neuropeptide derived from a large precursor and establish long term release, local to the transduced area, through the use of a VWF signal peptide.

\section{Methods}

\section{Cell lines and constructs}

Human embryonic kidney (HEK) 293T cells were maintained at $37^{\circ} \mathrm{C}$ with $5 \% \mathrm{CO}_{2}$ in Dulbecco's modified Eagles medium (DMEM) supplemented with 10\% fetal calf serum (FCS), $2 \mathrm{mM}$ glutamine, 100 units $/ \mathrm{ml}$ penicillin, 100 units $/ \mathrm{ml}$ streptomycin and non-essential amino acids.

pAAV-GFP with AAV2 inverted terminal resolutions sites, was previously described [34] and was a kind gift from M. Sena-Esteves. pAAV-flAgRP-ires-GFP (Figure 4) was constructed by cloning the full length mouse Agouti-related protein (AgRP) cDNA in pIRES2- 


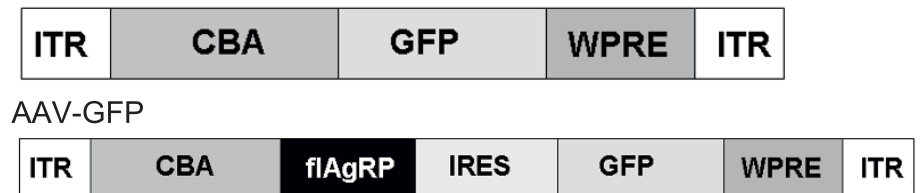

AAV-flAgRP

M L T A M L L S C V L L L A L P P T L G V Q M G V A P L K G I R R

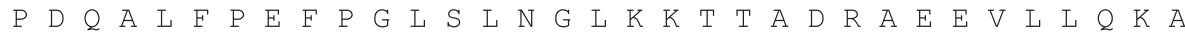

E A L A E V L D D P Q $N \begin{array}{lllllllllllllllllllllll}\boldsymbol{R} & \boldsymbol{E} & \boldsymbol{S} & \boldsymbol{R} & \mathrm{S} & \mathrm{P} & \mathrm{R} & \mathrm{R} & \mathrm{C} & \mathrm{V} & \mathrm{R} & \mathrm{L} & \mathrm{H} & \mathrm{E} & \mathrm{S} & \mathrm{C} & \mathrm{L} & \mathrm{G} & Q & \mathrm{Q} & \mathrm{V} & \mathrm{P}\end{array}$

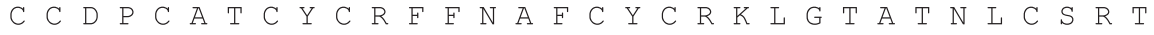

Stop

Endogenous signal peptide

Prohormone convertase recognition site

Signal peptide WWF

\begin{tabular}{|c|c|c|c|c|c|c|}
\hline ITR & CBA & $\mathrm{AgRP}_{83-132}$ & IRES & GFP & WPRE & ITR \\
\hline
\end{tabular}

HA tag

AAV-VWF-AgRP ${ }_{83-132}$

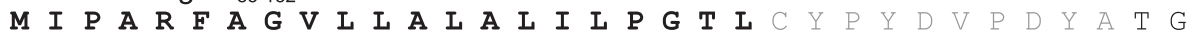

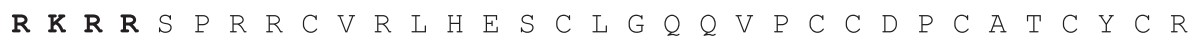

F F N A F C Y C R K L G T A T N L C S R T stop

Human VWF signal peptide

HA tag

Furine recognition site

Signal peptide WF

\begin{tabular}{|l|l|l|l|l|l|l|}
\hline ITR & CBA & MSH & IRES & GFP & WPRE & ITR \\
\hline \multicolumn{6}{|c}{ HA tag }
\end{tabular}

AAV-VWF- $\alpha-M S H 1$

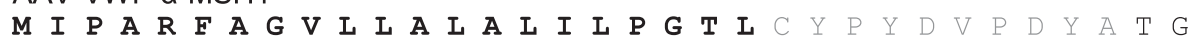

L T P P G S S S Y S ME H F R W G K P V P K P S T P E T Stop

Signal peptide WW

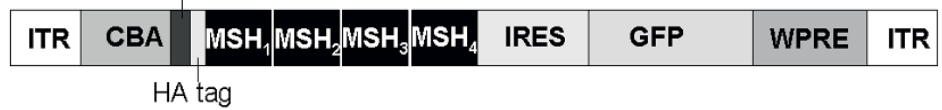

AAV-VWF-a-MSH4

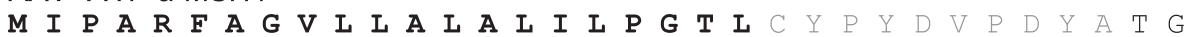

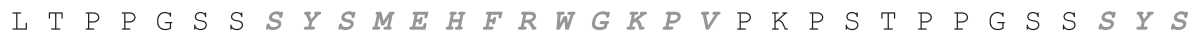

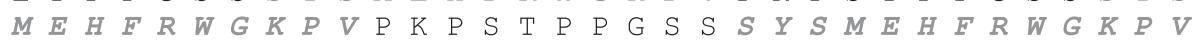

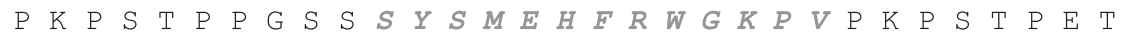

Stop

Human VWF signal peptide

HA tag

MSH

Figure 4 Vectors used in the study.

EGFP (Clontech). Subsequently, AgRP-ires-EGFP was isolated and ligated in pAAV-GFP, after removing GFP from the AAV plasmid. AgeI-furin-AgRP ${ }_{83-132}$-EcoRI was made by PCR on AgRP-ires-GFP with the following primers: Agrp83f: $5^{\prime}$ gatccaaccggtcgcaagcgtcgttctccgcgt cgctgtgtaa and ires reverse long: $5^{\prime}$ cggcttcggccagtaacgttagggggggggggagggaga. The PCR fragment was subsequently digested with AgeI and EcoRI and ligated into AgeI- EcoRI digested pCMV-VWF- $\alpha$ MSH4-ires-GFP resulting in pCMV-VWF-AgRP $83-132$-ires-GFP. pCMV-VWF- $\alpha$ MSH1-ires-GFP and pCMV-VWF$\alpha M S H 4-i r e s-G F P$ were described elsewhere [33]. The three pCMV-VWF-neuropeptide-ires-GFP vectors were digested with AfeI-BsrGI and the VWF-neuropeptideires-GFP parts were isolated and inserted in pAAV-GFP, resulting in pAAV-VWF-AgRP ${ }_{83-132}$, pAAV-VWF$\alpha M S H 1$ and pAAV-VWF- $\alpha$ MSH4 (Figure 4). Sequences were verified by sequence analysis. 
The pDP1 helper plasmid used to produce AAV vectors has been described [35] and was obtained from Plasmid factory (Bielefield, Germany).

\section{LacZ reporter gene assay}

Activation of the MC4R was determined using LacZ as a reporter gene [36]. DNA was transfected into cells with polyethylenimine [37]. Fifty nanograms of human MC4R and $10 \mu \mathrm{g}$ of cAMP-responsive element (CRE)-LacZ were transfected into $293 \mathrm{~T}$ cells on $10 \mathrm{~cm}$ dishes. Another five $10 \mathrm{~cm}$ dishes with $293 \mathrm{~T}$ cells were transfected with $10 \mu \mathrm{g}$ of respectively pAAV-GFP, pAAVflAgRP, pAAV-VWF-AgRP 83-132 , pAAV-VWF- $\alpha M S H 1$ and $\mathrm{pAAV}-\mathrm{VWF}-\alpha \mathrm{MSH} 4$. One day after transfection the MC4R_CRE-LacZ cells were transferred to poly-Llysine coated 96-wells plates. Three days after transfection supernatant of $10 \mathrm{~cm}$ dishes was removed and used for LacZ reporter assay. At this day the medium was removed from MC4R_CRE_LacZ transfected cells and replaced with assay buffer (DMEM containing $0.2 \%$ BSA, $25 \mathrm{mM}$ hepes and $30 \mu \mathrm{g} / \mathrm{ml}$ aprotinin) supplemented with NDP-MSH alone or in combination with conditioned supernatants of cells transfected with flAgRP, VWF-AgRP ${ }_{83-132}$ or GFP. In addition only forskolin was added to other wells as a positive control for CRE-LacZ transfection and the subsequent colometric reaction. The medium of another plate with MC4R_CRE-LacZ transfected cells was replaced with assay buffer containing serial dilutions of conditioned medium from cells transfected with $\alpha \mathrm{MSH} 1, \alpha \mathrm{MSH} 4$ or GFP. As assay controls only NDP-MSH or forskolin were added to other wells of this plate. After $5-6$ hour incubation at $37^{\circ} \mathrm{C}$ the assay medium was removed and replaced by $40 \mu \mathrm{l}$ lysisbuffer (phosphate buffered saline (PBS) containing 0.1\% Triton-X-100). The plates were stored at $-20^{\circ} \mathrm{C}$. After thawing of the plates, $80 \mu \mathrm{l}$ of substrate $(0.1 \mathrm{M}$ phosphate buffer, pH7.4, containing $1.6 \mathrm{~g} / \mathrm{l} o$-nitrophenyl $\beta$ D-galactopyranoside (ONPG, Invitrogen, the Netherlands), $67.5 \mathrm{mM} \beta$-mercaptoethanol (Merck, Germany) and $1.5 \mathrm{mM}$ magnesium chloride) was added to each well. Absorbance at $405 \mathrm{~nm}$ was measured in a Victor ${ }^{2}$ microplate reader (PerkinElmer, Brussels, Belgium).

\section{Spot blot}

To determine the amount of protein secreted into the medium of 293T cells transfected with flAgRP, VWF$\mathrm{AgRP}_{83-132}$ and GFP a spot blot was performed. A serial dilution of the medium was made in water. The first dilution was 20 times followed by 5 times dilutions. Subsequently $1 \mu \mathrm{l}$ of undiluted and diluted conditioned medium was spotted on Hybond-C extra. The blot was dried and blocked for 10 minutes in PBS containing 0.05\% Tween-20 (PBS-T) and 5\% milk. Afterwards the blot was incubated with a rabbit-AgRP antibody
(1:1.000; a kind gift of G. Barsh) in PBS-T for 90 minutes, washed three times 10 minutes with PBS-T and incubated for 60 minutes with goat-anti-rabbit horseradish peroxidase $(1: 20.000)$ in $\mathrm{PBS}-\mathrm{T}$. After three washes with PBS-T and one wash with PBS the spots were developed with SuperSignal West Dura extended duration substrate (Thermo scientific) and exposed to a CL-film.

\section{AAV production}

Each AAV production was performed with 15 dishes of $80-90 \%$ confluent $293 \mathrm{~T}$ cells at day of transfection. Two hours before transfection, the 10\% FCS-DMEM was replaced with $2 \%$ FCS-DMEM. The transfections were performed with polyethylenimine (PEI) as described by Reed S.E. et al. [37]. The pAAV plasmids were co-transfected helper plasmid pDp1 in a molar ratio of $1: 1$. The transfection mix remained on the cells until the next day, then the 2\% FCS-DMEM was refreshed. The purification was performed as described by Zolotukhin et al. [38]. The titer, in genomic copies per $\mathrm{ml}$ (g.c./ml), was determined by qPCR with sybergreen mix in a LightCylcer (Roche) [39]. The qPCR primers were designed to detect BGHpolyA and were BGHpolyA_F: 5' CCT CGACTGTGCCTTCTAG; BGHpolyA_R: 5' CCCCAGAATAGAATGACACCTA. The titers were AAV-GFPl $1 \times 10^{13}$ g.c. $/ \mathrm{ml}$; AAV-flAgRP $1.7 \times 10^{14}$ g.c. $/ \mathrm{ml}$ AAVVWF-AgRP ${ }_{83-132} 3 \times 10^{12}$ g.c./ml; AAV- $\alpha$ MSH4 $2.7 \times$ $10^{14}$ g.c. $/ \mathrm{ml}$. To obtain titer matched AAV preps, preps were diluted in PBS.

\section{Animals}

All experimental procedures were approved by the Committee for Animal Experimentation of the University of Utrecht (Utrecht, The Netherlands).

C57BL/6 mice were obtained from Charles River. Timed-pregnant mice were killed by means of cervical dislocation. The morning on which a vaginal plug was detected was considered embryonic day 0.5 (E0.5).

Male Wistar rats, weight ranging from 220-250 g, were purchased from Charles River. All rats were individually housed in filtertop cages with ad libitum access to food (CRM pellets; Special Diet Services, Whitham, Essex, UK) and water. Animals were kept in a temperature- and humidity-controlled room $\left(21 \pm 2^{\circ} \mathrm{C}\right)$ with a $12 \mathrm{~h}$ light/ dark cycle (lights on at 7:00 A.M.).

\section{Primary cortical neuron cultures}

Cerebral cortices of E16.5 mouse embryos were dissected and dissociated by incubation with $0.25 \%$ trypsin at $37^{\circ} \mathrm{C}$ for $10-15$ minutes, followed by tissue trituration with a fire-polished pasteurs pipet in DMEM containing $10 \% \mathrm{FCS}$ and $20 \mu \mathrm{g} / \mathrm{ml}$ DNAseI. After dissociation, the medium was removed and cells were resuspended in 
Neurobasal medium containing B27 supplement. Dissociated cells were plated at a density of 12.000 cells per well on poly-D-Lysin- (100 $\mu \mathrm{g} / \mathrm{ml}$; Sigma, Zwijndrecht, The Netherlands) and laminin- (40 $\mu \mathrm{g} / \mathrm{ml}$; Invitrogen, Breda, The Netherlands) coated glass coverslips in 24 well plates. Neuronal cultures were maintained in a humidified incubator at $37^{\circ} \mathrm{C}$ and $5 \% \mathrm{CO}_{2}$. After two days in culture, half of the medium was replaced with fresh maintenance medium (Neurobasal medium with B27). Two hours later neurons were infected with the different AAV vectors at multiplicity of infection 10.000 (thus $1.2 \times 10^{8}$ g.c. of AAV vector added per well). Seventy-two hours after infection neurons were washed twice with PBS, fixed with $4 \%$ paraformaldehyde for 30 minutes and stored in PBS at $4^{\circ} \mathrm{C}$.

\section{Immunohistochemistry}

Fixed neurons were washed twice with PBS. After 30 minutes incubation in block-t (PBS containing 1\% FCS and $0.1 \%$ Triton-X-100) neurons were incubated overnight with block-t containing rabbit anti-AgRP antibody (1:1000, a kind gift from G. Barsh) and mouse anti- $\beta$ III-tubulin $\left(1: 3000\right.$, Sigma) at $4^{\circ} \mathrm{C}$. The next day neurons were washed 3 times with PBS-t (PBS containing $0.1 \%$ Triton-X-100) and incubated for 60 minutes with secondary antibodies (goat-anti-mouse alexa555 (1:500) and goat-anti-rabbit alexa488 (1:500) (Invitrogen) in block buffer (PBS containing 1\% FCS). Afterwards neurons were washed 3 times with PBS, incubated with DAPI (1:3000, Sigma) for 5 minutes, washed 3 times with PBS and mounted in 90\% glycerol in PBS.

\section{In vivo AAV injections}

Six rats were anesthetized with fentanyl/fluanisone (Hypnorm, Janssen Pharmaceutica, Beerse, Belgium, $0.1 \mathrm{ml} / 100 \mathrm{~g}$ intramuscular). Carprofen (Rimadyl ${ }^{\circ}$, Pfizer Animal Health, Capelle a/d Ijssel, The Netherlands, 0.01 $\mathrm{ml} / 100 \mathrm{~g}$ subcutaneous) was administered as pain medication, before surgery and for 2 days after. Subsequently, the rats were injected unilaterally in the paraventricular nucleus (PVN, coordinates AP -1.80, ML +1.70, DV 8.10, angle 10 degrees) with $1 \mu \mathrm{l}$ of AAV-GFP or AAVVWF-AgRP $83-132$. The injected volume contained $1 \times 10^{9}$ g.c. of AAV vector and was delivered at a rate of $0.2 \mu \mathrm{l} /$ minute. Subsequently the injection the needle remained in the injection site for 10 minutes. Four weeks after injection the rats were decapitated, the brains were removed, quickly frozen on dry-ice and stored at $-80^{\circ} \mathrm{C}$ until they were sectioned on a cryostat (Leica, The Netherlands) at $20 \mu \mathrm{m}$, in series of 10 . Serie 1 was used for in situ hybridization with GFP-dig labeled mRNA probe to show the transduction area of the AAV vectors and serie 2 for a Nissl staining to show the overall morphology. The body weight and food intake data of animals with correct injection sites, as determined with GFP ISH, were used for behavioral analysis.

\section{In situ hybridization}

In situ hybridization was performed with a 720 basepair long digoxigenin (DIG)-labeled eGFP riboprobe (antisense to NCBI gene DQ768212) as described by Schaeren-Wiemers and Gerfin-Moser [40] with small modifications in the fixation procedure and hybridization temperature. Sections were fixed in $4 \%$ PFA for 20 minutes and hybridization was performed at $72^{\circ} \mathrm{C}$. After DIG in situ hybridization, slides were counterstained with $0.5 \%$ methyl green, quickly dehydrated in ethanol, cleared in xylene and mounted using Entellan.

\section{Data analysis}

Data were analyzed with GraphPad Prism (GraphPad Software Inc., California). Competition curves were fitted from duplicate data points using sigmoidal dose response curve with variable slope.

Body weight gain and food intake were tested with two sided $t$-test.

\section{Acknowledgements}

This work was supported by the Netherlands Organization for Scientific Research (NWO grant No. 90339175).

\section{Authors' contributions}

MWAdB constructed the AAV vectors, produced and purified them with the help of KGM. MWAdB performed and analyzed LacZ reporter assays, spot blot, immunohistochemstry and in situ hybridizations; discussed the results and prepared the manuscript. MADB and MCML performed the animal work including stereotaxic injections. DMAvdH and RJP provided the primary cortical cultures to MWAdB to transduce them and have discussed the results. $\mathrm{RAH}$ participated in experimental design and supervised the experiments, discussed results, corrected the manuscript and provided financial support. All authors have read and approved the final manuscript.

Received: 25 January 2010 Accepted: 11 August 2010 Published: 11 August 2010

\section{References}

1. Nillni EA: Regulation of prohormone convertases in hypothalamic neurons: implications for prothyrotropin-releasing hormone and proopiomelanocortin. Endocrinology 2007, 148:4191-4200.

2. Pritchard LE, White $A$ : Neuropeptide processing and its impact on melanocortin pathways. Endocrinology 2007, 148:4201-4207.

3. Winsky-Sommerer R, Benjannet S, Rovere C, Barbero P, Seidah NG Epelbaum J, Dournaud P: Regional and cellular localization of the neuroendocrine prohormone convertases PC1 and PC2 in the rat central nervous system. J Comp Neurol 2000, 424:439-460.

4. Fernandez CJ, Haugwitz M, Eaton B, Moore HP: Distinct molecular events during secretory granule biogenesis revealed by sensitivities to brefeldin A. Mol Biol Cell 1997, 8:2171-2185.

5. Kask A, Rago L, Wikberg JE, Schioth HB: Differential effects of melanocortin peptides on ingestive behaviour in rats: evidence against the involvement of $M C(3)$ receptor in the regulation of food intake. Neurosci Lett 2000, 283:1-4. 
6. Smith ML, Prall B, Nandar W, Cline MA: Beta-melanocyte-stimulating hormone potently reduces appetite via the hypothalamus in chicks. J Neuroendocrinol 2008, 20:220-226.

7. McMinn JE, Wilkinson CW, Havel PJ, Woods SC, Schwartz MW: Effect of intracerebroventricular alpha-MSH on food intake, adiposity, c-Fos induction, and neuropeptide expression. Am J Physiol Regul Integr Comp Physiol 2000, 279:R695-R703.

8. Silva RM, Hadjimarkou MM, Rossi GC, Pasternak GW, Bodnar RJ: Betaendorphin-induced feeding: pharmacological characterization using selective opioid antagonists and antisense probes in rats. J Pharmacol Exp Ther 2001, 297:590-596.

9. Grandison L, Guidotti A: Stimulation of food intake by muscimol and beta endorphin. Neuropharmacology 1977, 16:533-536.

10. Yaswen L, Diehl N, Brennan MB, Hochgeschwender U: Obesity in the mouse model of pro-opiomelanocortin deficiency responds to peripheral melanocortin. Nat Med 1999, 5:1066-1070.

11. Appleyard SM, Hayward M, Young Jl, Butler AA, Cone RD, Rubinstein M, Low MJ: A role for the endogenous opioid beta-endorphin in energy homeostasis. Endocrinology 2003, 144:1753-1760.

12. Zhang JV, Ren PG, Avsian-Kretchmer O, Luo CW, Rauch R, Klein C, Hsueh AJ: Obestatin, a peptide encoded by the ghrelin gene, opposes ghrelin's effects on food intake. Science 2005, 310:996-999.

13. Tiesjema B, Adan RA, Luijendijk MC, Kalsbeek A, la Fleur SE: Differential effects of recombinant adeno-associated virus-mediated neuropeptide $Y$ overexpression in the hypothalamic paraventricular nucleus and lateral hypothalamus on feeding behavior. J Neurosci 2007, 27:14139-14146.

14. Klein RL, Hamby ME, Gong Y, Hirko AC, Wang S, Hughes JA, King MA Meyer EM: Dose and promoter effects of adeno-associated viral vector for green fluorescent protein expression in the rat brain. Experimental Neurology 2002, 176:66-74

15. Li G, Zhang Y, Wilsey JT, Scarpace PJ: Hypothalamic pro-opiomelanocortin gene delivery ameliorates obesity and glucose intolerance in aged rats. Diabetologia 2005, 48:2376-2385.

16. Tiesjema B, la Fleur SE, Luijendijk MC, Adan RA: Sustained NPY overexpression in the PVN results in obesity via temporarily increasing food intake. Obesity (Silver Spring) 2009, 17:1448-1450.

17. Wise RJ, Dorner AJ, Krane M, Pittman DD, Kaufman RJ: The role of von Willebrand factor multimers and propeptide cleavage in binding and stabilization of factor VIII. J Biol Chem 1991, 266:21948-21955.

18. Sporn LA, Marder VJ, Wagner DD: Inducible secretion of large, biologically potent von Willebrand factor multimers. Cell 1986, 46:185-190

19. Takahashi S, Nakagawa T, Banno T, Watanabe T, Murakami K, Nakayama K: Localization of furin to the trans-Golgi network and recycling from the cell surface involves Ser and Tyr residues within the cytoplasmic domain. J Biol Chem 1995, 270:28397-28401.

20. Thomas G: Furin at the cutting edge: from protein traffic to embryogenesis and disease. Nat Rev Mol Cell Biol 2002, 3:753-766.

21. Schafer MK, Day R, Cullinan WE, Chretien M, Seidah NG, Watson SJ: Gene expression of prohormone and proprotein convertases in the rat CNS: a comparative in situ hybridization analysis. J Neurosci 1993, 13:1258-1279.

22. Creemers JW, Pritchard LE, Gyte A, Le Rouzic P, Meulemans S, Wardlaw SL, Zhu X, Steiner DF, Davies N, Armstrong D, et al: Agouti-related protein is posttranslationally cleaved by proprotein convertase 1 to generate agouti-related protein (AGRP)83-132: interaction between AGRP83-132 and melanocortin receptors cannot be influenced by syndecan-3. Endocrinology 2006, 147:1621-1631.

23. Nijenhuis WA, Oosterom J, Adan RA: AgRP(83-132) acts as an inverse agonist on the human-melanocortin-4 receptor. Mol Endocrinol 2001, 15:164-171.

24. Hagan MM, Rushing PA, Pritchard LM, Schwartz MW, Strack AM, Van der Ploeg LH, Woods SC, Seeley RJ: Long-term orexigenic effects of AgRP(83-132) involve mechanisms other than melanocortin receptor blockade. Am J Physiol Regul Integr Comp Physiol 2000, 279:R47-R52.

25. Small CJ, Liu YL, Stanley SA, Connoley IP, Kennedy A, Stock MJ, Bloom SR: Chronic CNS administration of Agouti-related protein (Agrp) reduces energy expenditure. Int J Obes Relat Metab Disord 2003, 27:530-533.

26. Pierroz DD, Ziotopoulou M, Ungsunan L, Moschos S, Flier JS, Mantzoros CS: Effects of acute and chronic administration of the melanocortin agonist MTII in mice with diet-induced obesity. Diabetes 2002, 51:1337-1345.

27. Lee EJ, Lee SH, Jung JW, Lee W, Kim BJ, Park KW, Lim SK, Yoon CJ, Baik JH: Differential regulation of CAMP-mediated gene transcription and ligand selectivity by MC3R and MC4R melanocortin receptors. Eur J Biochem 2001, 268:582-591.

28. El Meskini R, Jin L, Marx R, Bruzzaniti A, Lee J, Emeson R, Mains R: A signal sequence is sufficient for green fluorescent protein to be routed to regulated secretory granules. Endocrinology 2001, 142:864-873.

29. Pouli AE, Kennedy HJ, Schofield JG, Rutter GA: Insulin targeting to the regulated secretory pathway after fusion with green fluorescent protein and firefly luciferase. Biochem J 1998, 331(Pt 2):669-675.

30. Haberman RP, Samulski RJ, McCown TJ: Attenuation of seizures and neuronal death by adeno-associated virus vector galanin expression and secretion. Nat Med 2003, 9:1076-1080.

31. Gasmi M, Herzog CD, Brandon EP, Cunningham JJ, Ramirez GA, Ketchum ET, Bartus RT: Striatal delivery of neurturin by CERE-120, an AAV2 vector for the treatment of dopaminergic neuron degeneration in Parkinson's disease. Mol Ther 2007, 15:62-68.

32. Foti SB, Samulski RJ, McCown TJ: Delivering multiple gene products in the brain from a single adeno-associated virus vector. Gene Ther 2009, 16:1314-1319.

33. Tiesjema B, Merkestein M, Garner KM, de Krom M, Adan RA: Multimeric alpha-MSH has increased efficacy to activate the melanocortin MC4 receptor. Eur J Pharmacol 2008, 585:24-30.

34. Broekman MLD, Comer LA, Hyman BT, Siena-Esteves M: Adeno-associated virus vectors serotyped with AAV8 capsid are more efficient than AAV-1 or-2 serotypes for widespread gene delivery to the neonatal mouse brain. Neuroscience 2006, 138:501-510.

35. Grimm D, Kay MA, Kleinschmidt JA: Helper virus-free, optically controllable, and two-plasmid-based production of adeno-associated virus vectors of serotypes 1 to 6 . Mol Ther 2003, 7:839-850.

36. Chen W, Shields TS, Stork PJ, Cone RD: A colorimetric assay for measuring activation of Gs- and Gq-coupled signaling pathways. Anal Biochem 1995, 226:349-354

37. Reed SE, Staley EM, Mayginnes JP, Pintel DJ, Tullis GE: Transfection of mammalian cells using linear polyethylenimine is a simple and effective means of producing recombinant adeno-associated virus vectors. Journal of Virological Methods 2006, 138:85-98.

38. Zolotukhin S, Potter M, Zolotukhin I, Sakai Y, Loiler S, Fraites TJ Jr, Chiodo VA, Phillipsberg T, Muzyczka N, Hauswirth WW, et al: Production and purification of serotype 1,2 , and 5 recombinant adeno-associated viral vectors. Methods 2002, 28:158-167.

39. Veldwijk MR, Topaly J, Laufs S, Hengge UR, Wenz F, Zeller WJ, Fruehauf S: Development and optimization of a real-time quantitative PCR-based method for the titration of AAV-2 vector stocks. Mol Ther 2002, 6:272-278.

40. Schaeren-Wiemers N, Gerfin-Moser A: A single protocol to detect transcripts of various types and expression levels in neural tissue and cultured cells: in situ hybridization using digoxigenin-labelled cRNA probes. Histochemistry 1993, 100:431-440.

doi:10.1186/1471-2202-11-94

Cite this article as: de Backer et al:: Neuropeptide delivery to the brain: a von Willebrand factor signal peptide to direct neuropeptide secretion. BMC Neuroscience 2010 11:94.

\section{Submit your next manuscript to BioMed Central and take full advantage of:}

- Convenient online submission

- Thorough peer review

- No space constraints or color figure charges

- Immediate publication on acceptance

- Inclusion in PubMed, CAS, Scopus and Google Scholar

- Research which is freely available for redistribution 